\title{
Berenice Bonhomme, Triptyque de Claude Simon. Du livre au film. Une esthétique du passage
}

\section{Elisa Bricco}

\section{(2) OpenEdition}

\section{Edizione digitale}

URL: http://journals.openedition.org/studifrancesi/28058

DOI: 10.4000/studifrancesi.28058

ISSN: 2421-5856

\section{Editore}

Rosenberg \& Sellier

\section{Edizione cartacea}

Data di pubblicazione: 31 décembre 2006

Paginazione: 638

ISSN: 0039-2944

\section{Notizia bibliografica digitale}

Elisa Bricco, «Berenice Bonhomme, Triptyque de Claude Simon. Du livre au film. Une esthétique du passage », Studi Francesi [Online], 150 (L | III) | 2006, online dal 30 novembre 2015, consultato il 08 novembre 2020. URL : http://journals.openedition.org/studifrancesi/28058 ; DOI : https://doi.org/ 10.4000/studifrancesi.28058

\section{Questo documento è stato generato automaticamente il 8 novembre 2020}

\section{(c) (1)}

Studi Francesi è distribuita con Licenza Creative Commons Attribuzione - Non commerciale - Non opere derivate 4.0 Internazionale. 


\title{
Berenice Bonhomme, Triptyque de Claude Simon. Du livre au film. Une esthétique du passage
}

\author{
Elisa Bricco
}

\section{NOTIZIA}

BERENICE BONHOMme, Triptyque de Claude Simon. Du livre au film. Une esthétique du passage, Bari-Paris, Schena-Presses de l'université de Paris-Sorbonne, 2005, pp. 223.

1 Il sottotitolo di questo interessante saggio è assolutamente illustrativo della tematica affrontata e delle modalità dell'analisi comparativa svolta dall'A.

2 Testimone di un'epoca in cui il cinema ha affascinato e influenzato la scrittura aprendole nuove possibilità espressive, già ampiamente sondate da Duras e RobbeGrillet, Claude Simon si è misurato con la trasposizione filmica di un suo testo, Triptyque. Come annunciato nell'introduzione, la problematica che sottende questa ricerca comporta l'indagine sulle capacità dell'opera d'arte di «rendre compte du réel» (p. 11). A partire da questo presupposto, l'A. dimostra come lo scrittore tenti una sintesi tra diverse forme artistiche: romanzo, poesia e cinema.

3 La problematica del passaggio e dell'adattamento ritorna in ognuna delle tre parti del saggio che viene introdotta dall'analisi-lettura di una fotografia scattata dallo stesso Claude Simon. Momento emblematico della captazione del reale, la fotografia si caratterizza per la capacità di fissare e memorizzare istantanee che sfuggono alla memoria umana con il passare del tempo, e, come si sa, lo scrittore ha utilizzato la fotografia nei suoi romanzi.

4 Nelle tre parti sono prese in esame dapprima le questioni relative al passaggio da un linguaggio all'altro e da un sistema enunciativo ad un altro; in seguito vengono descritte le attività di montaggio e di costruzione delle due opere e si rileva un presupposto metaforico che guida le scelte dello scrittore; infine l'ultima parte è 
dedicata all'osservazione delle dinamiche della creazione che si possono sintetizzare con la messa in scena della tensione tra "destruction et espoir».

5 Attraverso l'analisi del passaggio dal testo alla pellicola, l'A. mette in luce la profonda riflessione dello scrittore alla ricerca di un nuovo linguaggio di sintesi delle capacità espressive dei due media. Il film infatti non è l'esatta riproduzione visiva del testo, bensì una vera e propria trasposizione, riscrittura per immagini del significato testuale. Il corto-metraggio dunque fa appello all'empatia, all'adesione dello spettatore che partecipa personalmente alla materia narrata/osservata, ne è affascinato, e, addirittura, il potere fascinatorio delle immagini ha la meglio sulla storia narrata che passa così in secondo piano.

6 Il volume è corredato dal riassunto del testo, dallo story board del corto-metraggio e da un'intervista allo scrittore. 